\title{
Diagnostic value of endoscopic and endoscopic ultrasound characteristics of duodenal submucosal tumour-like heterotopic gastric mucosa
}

\author{
Koichi Eguchi MD PhD ${ }^{1}$, Kunihiko Aoyagi MD PhD¹, Satoshi Nimura MD PhD², Shotaro Sakisaka MD PhD ${ }^{1}$
}

\begin{abstract}
K Eguchi, K Aoyagi, S Nimura, S Sakisaka. Diagnostic value of endoscopic and endoscopic ultrasound characteristics of duodenal submucosal tumour-like heterotopic gastric mucosa. Can J Gastroenterol 2011;25(7):365-367.
\end{abstract}

OBJECTIVE: Recent studies have reported that duodenal heterotopic gastric mucosa (HGM) has been observed in $8.9 \%$ of patients who undergo esophagogastroduodenoscopy. However, there are few reports concerning the endoscopic and endoscopic ultrasound characteristics of submucosal tumour-like HGM in the duodenum.

METHODS: Endoscopic, endoscopic ultrasound (EUS) and histological findings were analyzed in six patients with submucosal tumour-like HGM, which were confirmed by pathological examination of biopsy or endoscopic polypectomy specimens.

RESULTS: Endoscopically, the lesions appeared as a solitary, sessile submucosal tumour-like mass with a depression at the top. In four of six patients, small granular structures were found in the depressed area of the mass. On EUS, all masses demonstrated a heterogeneous pattern, among which four patients presented anechoic areas while two patients showed no anechoic areas. All lesions were localized within the mucosa and submucosa on EUS. Histologically, they consisted of gastric glands and some dilated glands, and were covered with normal duodenal epithelium. In four of six lesions, the tumours were composed of gastric-type foveolar epithelium showing papillary growth, fundic glands and pyloric glands, while the others consisted of gastric-type foveolar epithelium and pyloric glands.

CONCLUSION: A heterogeneous pattern on EUS and small granular structures on esophagogastroduodenoscopy represent valuable diagnostic features of submucosal tumour-like HGM.

Key Words: Duodenal submucosal tumour; Endoscopic ultrasound; Heterotopic gastric mucosa

$\mathrm{T}$ he presence of heterotopic gastric mucosa (HGM) is well known in all organs of the gastrointestinal tract, particularly in the esophagus, duodenum and ileum (Meckel's diverticulum) (1-4). A recent study (5) observed duodenal HGM in $8.9 \%$ of 28,210 patients who underwent esophagogastroduodenoscopy (EGD), and is endoscopically recognized as solitary or multiple small nodules $(4,6,7)$. Morphologically, submucosal tumour-like masses are frequently of the solitary type (2,7-9). Solitary large HGMs may be difficult to differentiate from malignant neoplasms such as carcinoma, carcinoid tumours or lymphoma (1); however, a differential diagnosis for it has yet to be established.

Herein, we describe the endoscopic and endoscopic ultrasound (EUS) features of six cases of duodenal HGM with submucosal tumour-like appearance in the bulb and descending duodenum.

\section{METHODS}

Patients

Six patients with histologically proven duodenal HGM were evaluated by EGD and EUS. HGM was defined as a lesion consisting of gastric-type foveolar epithelium and/or fundic glands containing
La valeur diagnostique des caractéristiques des endoscopies et des échographies endoscopiques de la sous-muqueuse duodénale de la muqueuse gastrique hétérotopique d'aspect tumoral

OBJECTIF : Selon des études récentes, on observe une muqueuse gastrique hétérotopique $(\mathrm{MGH})$ du duodénum chez $8,9 \%$ des patients qui ont subi une œesophagogastroduodénoscopie. Cependant, peu de rapports portent sur les caractéristiques des endoscopies et des échographies endoscopiques de la sous-muqueuse duodénale de la MGH d'aspect tumoral.

MÉTHODOLOGIE : Les auteurs ont analysé les observations de l'endoscopie, de l'échographie endoscopique (ÉES) et de l'histologie chez six patients ayant une sous-muqueuse de la MGH d'aspect tumoral, confirmée par examen pathologique des prélèvements de biopsie ou de polypectomie endoscopique.

RÉSULTATS : Sur le plan endoscopique, les lésions prenaient la forme d'une masse sous-muqueuse solitaire et sessile d'aspect tumoral surmontée d'une dépression. Chez quatre des six patients, on observait de petites structures granulaires dans la zone déprimée de la masse. À l'ÉES, toutes les masses avaient un aspect hétérogène, caractérisé par des zones anéchoïques chez quatre patients et par l'absence de zones anéchoïques chez deux patients. D'après l'ÉES, toutes les lésions étaient situées dans la muqueuse et la sous-muqueuse. Sur le plan histologique, elles se composaient de glandes gastriques et de quelques glandes dilatées et étaient couvertes d'épithélium duodénal normal. Dans quatre des six lésions, les tumeurs se composaient d'épithélium fovéolaire de type gastrique comportant une croissance papillaire, des glandes fondiques et des glandes pyloriques, tandis que les deux autres se composaient d'épithélium fovéolaire de type gastrique et de glandes pyloriques.

CONCLUSION : Un modèle hétérogène d'après l'ÉES et de petites structures granulaires d'après l'œsophagogastroduodénoscopie représentent des caractéristiques diagnostiques précieuses de la $\mathrm{MGH}$ d'aspect tumoral de la sous-muqueuse.

parietal cells and chief cells. The patients included six men, ranging in age from 49 to 71 years, all of whom presented with unremarkable symptoms. Two patients were referred for endoscopy due to undiagnosed gastric tumours, one for follow-up examination of gastric ulcer, one for further examination of gastric cancer, one for papillary cancer and one for colon cancer. All duodenal HGMs were incidental findings during endoscopy.

All of the patients underwent routine EGD (GIF-Q240, GIFQ260, Olympus Optical Co, Japan) followed by EUS using a miniature probe system (12 MHz to $20 \mathrm{MHz}$; UM2R, UM3R, Olympus, Japan) after a fast of $12 \mathrm{~h}$ or longer. All patients received a single $20 \mathrm{mg}$ intramuscular bolus of scopolamine butylbromide (Buscopan [Boehringer, Japan]) before endoscopy.

EUS images were obtained after filling the spaces around the lesions with deaerated (boiled) water. At each examination, 10 to 15 photographs were taken for analysis of size, echo level, borders of the lesions and layer of origin. Because it was difficult to exclude carcinoid tumour or carcinoma with submucosal growth patterns, three lesions (from patients 1, 2 and 3) were removed by endoscopic polypectomy and subsequently diagnosed histologically as HGM. Biopsy specimens of

${ }^{1}$ Department of Gastroenterology and Medicine; ${ }^{2}$ Department of Pathology, Fukuoka University School of Medicine, Fukuoka, Japan

Correspondence and reprints: Dr Koichi Eguchi, Department of Gastroenterology and Medicine, Fukuoka University School of Medicine,

7-45-1, Nanakuma, jounan-ku, Fukuoka city, Japan. Telephone 81-92-801-1011, fax 81-92-874-2663, e-mail keguchi@minf.med.fukuoka-u.ac.jp

Received for publication May 19, 2010. Accepted November 22, 2010 
TABLE 1

Endoscopic, endoscopic ultrasound and histological findings in six men with duodenal heterotopic gastric mucosa

\begin{tabular}{|c|c|c|c|c|c|c|c|c|c|}
\hline \multirow{3}{*}{$\begin{array}{l}\text { Patient: } \\
\text { age } \\
\text { (years) }\end{array}$} & \multirow{2}{*}{\multicolumn{4}{|c|}{ Endoscopy }} & \multicolumn{4}{|c|}{ Endoscopic ultrasound } & \multirow{3}{*}{ Histology } \\
\hline & & & & & \multirow{2}{*}{\multicolumn{2}{|c|}{$\begin{array}{l}\text { Location Size*, } \\
\text { (layer) mm }\end{array}$}} & \multirow{2}{*}{\multicolumn{2}{|c|}{$\begin{array}{cc}\text { Anechoic } \\
\text { Internal echo } \\
\text { lesion }\end{array}$}} & \\
\hline & Portion & Configuration & Surface & Top & & & & & \\
\hline $1: 71$ & 2nd & SMT-like mass & Normal mucosa & Depressed granular & II-III & $11 \times 8$ & Heterogenous & + & Foveolar epithelium, fundic glands, pyloric gland \\
\hline 2: 49 & Bulb & SMT-like mass & Normal mucosa & Depressed granular & II-III & $12 \times 10$ & Heterogenous & + & Foveolar epithelium, pyloric gland \\
\hline 3: 78 & 2nd & SMT-like mass & Normal mucosa & Depressed flat & II-III & $16 \times 8$ & Heterogenous & + & Foveolar epithelium, pyloric gland \\
\hline 4: 68 & 2nd & SMT-like mass & Normal mucosa & Depressed flat & II-III & $7 \times 6$ & Heterogenous & + & Foveolar epithelium, fundic glands, pyloric gland \\
\hline 5: 54 & 2nd & SMT-like mass & Normal mucosa & Depressed granular & II-III & $11 \times 6$ & Heterogenous & + & Foveolar epithelium, fundic glands, pyloric gland \\
\hline 6: 64 & Bulb & SMT-like mass & Normal mucosa & Depressed granular & II-III & $13 \times 6$ & Heterogenous & $\mathrm{N} / \mathrm{A}$ & Foveolar epithelium, fundic glands, pyloric gland \\
\hline
\end{tabular}

*Width $\times$ height. + Positive; N/A Not available; SMT Submucosal tumour

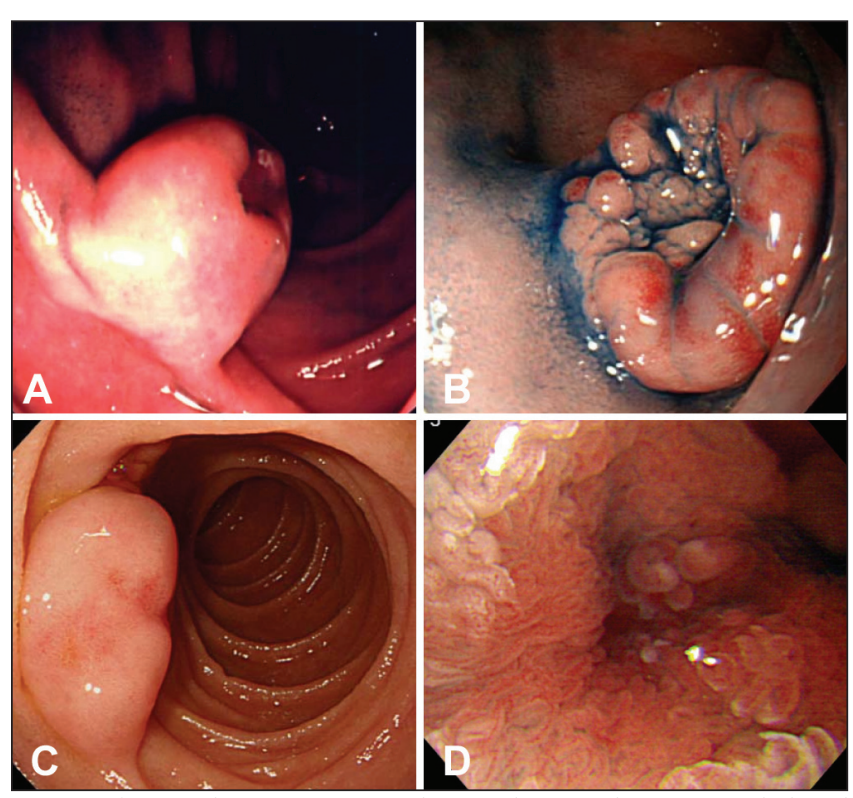

Figure 1) A and B: Patient 1 and 6. Endoscopy showing a wide-based sessile submucosal tumour-like mass with depression at the top of the lesion. The lesions are covered mainly by normal duodenal mucosa. C Patient 3. Endoscopy showing a wide-based sessile submucosal tumour-like mass without granular structures at the top of the lesion. D Patient 4. Small granular structures are found in the depressed area
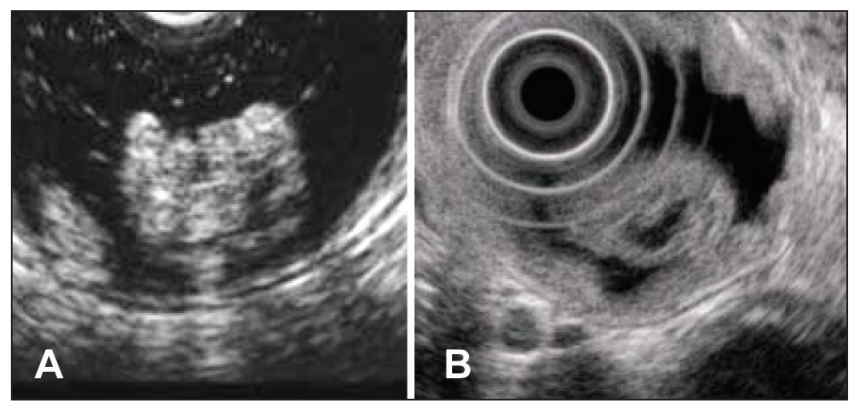

Figure 2) A Patient 1. Endoscopic ultrasound images showing a heterogeneously hyperechoic mass with several anechoic lesions located predominantly in the submucosa. B Patient 3. Endoscopic ultrasound image showing a heterogeneously hyperechoic mass with anechoic lesions located predominantly in the submucosa

three lesions removed endoscopically from patients 4, 5 and 6 were diagnosed as HGM.

\section{RESULTS}

The clinical, endoscopic and EUS results are summarized in Table 1. The affected sites were the descending duodenum in four patients and the bulb in two. Endoscopically, the lesions appeared as solitary,

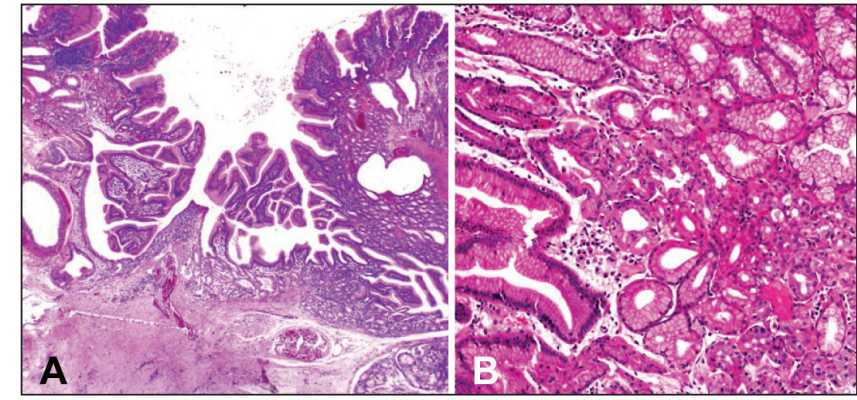

Figure 3) A Patient 1. Histological examination of a polypectomy specimen showing the lesion covered by normal duodenal mucosa consisting of gastrictype foveolar epithelium, gastric fundic glands and pyloric glands with some dilated glands. B Patient 4. Biopsy specimen showing a lesion consisting of gastric fundic glands and pyloric glands

sessile, submucosal tumour-like masses with a wide base and a depression at the top of the lesion (Figures $1 \mathrm{~A}, 1 \mathrm{~B}$ and $1 \mathrm{C}$ ). The remaining surface of the masses was covered mainly with normal duodenal mucosa. In four of six lesions analyzed, small granular structures were found in the depressed area (Figure 1D).

On EUS, the tumours were demonstrated to be heterogeneously hypoechoic masses with small anechoic areas (Figures 2A and 2B). The tumours ranged from $6 \mathrm{~mm}$ to $16 \mathrm{~mm}$ in diameter, and were localized within the second to third layers, which appeared to correspond to the mucosa and submucosa, respectively.

Histologically, all lesions consisted of gastric glands with or without some dilated glands, which were visualized as small anechoic areas on EUS (Figures 2A and 2B) and covered with normal duodenal epithelium without metaplastic change (Figure 3A). In four cases, tumours were composed of gastric-type foveolar epithelium showing papillary growth involving the fundic glands and pyloric glands (Figure 3B). The others consisted of gastric-type foveolar epithelium and pyloric glands. No atypical cells were observed in any cases. No tumour recurrence developed in the three patients who underwent polypectomy.

\section{DISCUSSION}

Jepsen et al (10) reported that duodenal polyps were found in $4.6 \%$ of patients referred for upper endoscopy, and that $1.4 \%$ of these duodenal polyps were HGM. A more recent study (5) reported a prevalence of duodenal HGM of $8.9 \%$ in patients undergoing EGD.

Histologically, previous reports $(4,6,7)$ described HGM as comprised of solitary or multiple nodules. The proportion of the latter exceed $70 \%$, whereas that of solitary lesions was small and ranged from $0 \%$ to $30 \%$. Uraoka et al (7) described solitary lesions as hemispherically shaped and approximately $10 \mathrm{~mm}$ in diameter. Conversely, multiple-type lesions were demonstrated to be small nodules of various sizes. Each nodule exhibited an ovoid shape and plate-like elevation, with a diameter of $2 \mathrm{~mm}$ to $5 \mathrm{~mm}$. In the present report, we described six cases of hemispherical HGM with a submucosal tumour-like appearance. Similar endoscopic findings of HGM have been reported by other investigators (2,7-9). Possible differential diagnoses include Brunner's gland 
hyperplasia, ectopic pancreatic tissue, benign lymphoid hyperplasia, lymphoma, leiomyoma, leiomyosarcoma, adenoma, carcinoma and carcinoid tumours $(1,8)$.

In the present series, a unique endoscopic finding was identified in $66 \%$ of patients, specifically small granular or lobular structures within the depressed portion of the lesion. Some investigators reported that large solitary duodenal HGMs tended to exhibit central depression $(7,9,11)$. However, these features can also be seen in Brunner's gland hyperplasia, carcinoid tumour, metastatic neoplasm or malignant lymphoma $(1,8,9)$. Thus, it may be difficult to distinguish duodenal HGMs from other submucosal tumours using endoscopy.

EUS provides valuable information for the diagnosis of submucosal tumours of the gastrointestinal tract (12) because it is able to safely and precisely visualize size, extent, the layer of origin of the lesions and obtain internal images precisely (13). However, specific EUS features of duodenal HGMs are scarce. Hizawa et al (14) described that duodenal HGMs reveal simple anechoic masses within the submucosal layer on EUS. The EUS findings in our cases included hypoechoic and several small anechoic areas predominantly within the submucosal layer. We believe that the internal echo pattern of HGMs is variable and in accordance with the size of dilated gastric-type glands, which is characteristic of HGM.

An alternative approach for the differential diagnosis of HGM is Tc-99m pertechnetate scintigraphy. Tc-99m pertechnetate abdominal

\section{REFERENCES}

1. Vizcarrondo FJ, Wang TY, Brady PG. Heterotopic gastric mucosa: Presentation as a rugose duodenal mass. Gastrointest Endosc 1983;29:107-11.

2. Kundrotas LW, Camara DS, Meenaghan MA, et al. Heterotopic gastric mucosa: A case report. Am J Gastroenterol 1985;80:253-6.

3. Bernheim J, Novis BH. Heterotopic and metaplastic gastric mucosa in the duodenum. Isr J Med Sci 1989;25:321-3.

4. Langkemper R, Hoek AC, Dekker W, et al. Elevated lesions in the duodenal bulb caused by heterotopic gastric mucosa. Radiology 1980;137:621-4.

5. Genta RM, Kinsey RS, Singhal A, et al. Gastric foveolar metaplasia and gastric heterotopia in the duodenum: No evidence of an etiologic role for Helicobacter pylori. Human Pathol 2010;41:1593-600.

6. Lessells AM, Martin DF. Heterotopic gastric mucosa in the duodenum. J Clin Pathol 1982;35:591-5.

7. Uraoka M, Fujitani T, Iida M, et al. Clinico-pathological investigation of heterotopic gastric mucosa of the duodenum. Gastroenterol Endosc 1986;28:3078-85 (in Japanese with English abstract).

8. Shiraishi S, Yasuda K, Bandoh T, et al. Laparoscopic resection for ectopic gastric mucosa of the duodenum: Report of a case. Surg Today 1999;29:351-3.

9. Kawamoto K, Ushio K, Ino S, et al. Diagnosis of neoplastic-like duodenal small lesions, adenoma and cancer (in Japanese). Stom Intest 2001;36:1507-27.

10. Jepsen JM, Perssen M, Jakobsen NO, et al. Prospective study of prevalence and endscopic and histopathologic characteristics of scintigraphy is a useful method for diagnosing and locating ectopic gastric mucosa in Meckel's diverticulum, enteric or gastric duplications and cysts, Barrett's esophagus and islands of HGM in an otherwise normal bowel. The method has an overall accuracy of $90 \%$ and a sensitivity of $85 \%$ in surgically proven cases (15).

Excessive surgery should be avoided because HGM is essentially a benign entity. However, if the HGM is large, it may still require laparoscopic or endoscopic resection due to the risk of ulceration, bleeding, adenoma or adenocarcinoma in the HGM, as previously reported (8,9,16-18). Endoscopic resection may be applied in the case of duodenal HGMs when EUS can verify that the tumour is localized in the third layer, which corresponds to the submucosa of the duodenal wall. EUS demonstrated that three lesions (patients 1, 2 and 3) were localized in the mucosa and submucosa. We carefully performed endoscopic polypectomy with electrocautery snare for removal, and obtained precise histological diagnosis of the tumours. These three patients developed no complications from the resection.

\section{CONCLUSION}

We showed that heterogeneously hypoechoic masses with several small anechoic lesions on EUS, and small granular structures on the depressed portions of the lesion, may be a characteristic feature of HGMs. Finally, EUS may not only provide characteristic findings, but also indicate the appropriateness of endoscopic resection.

duodenal polyps is patients submitted to upper endoscopy. Scand J Gastroenterol 1994;29:483-7.

11. Yoshimitsu K, Yoshida M, Motooka M, et al. Heterotopic gastric mucosa of the duodenum mimicking a duodenal cancer. Gastrointest Radiol 1989;14;115-7.

12. Kawamoto K, Ueyama T, Iwashita I, et al. Colonic submucosal tumors, comparison of endoscopic US and target air-enema CT with barium enema study and colonoscopy. Radiology 1994;192:697-702.

13. Rösch T, Lorenz R, Dancygier H, et al. Endosonographic diagnosis of submucosal upper gastrointestinal tract tumors. Scan J Gastroenterol 1992;27:1-8.

14. Hizawa K, Matsumoto T, Kouzuki T, et al. Cystic submucosal tumors in the gastrointestinal tract: Endosonographic findings and endoscopic removal. Endoscopy 2000;32:712-4.

15. Sfakianakis GN, Conway JJ. Detection of ectopic gastric mucosa in Meckel's diverticulum and in other aberrations by scintigraphy. II. Indications and methods-a 10 year experience. J Nucl Med 1981;22:732

16. Russin V, Krevsky B, Caroline DF, et al. Mixed hyperplastic and adenomatous polyp arising from ectopic gastric mucosa of the duodenum. Arch Pathol Lab Med 1986;110:556-8.

17. Pasic F, Kesic V, Jokic A, et al. Duodenal polyps of gastric origin. Med Arch 1993;47:95-6.

18. Kushima R, Ruthlein HJ, Stolte M, et al. Pyloric gland-type adenoma arising in heterotopic gastric mucosa of the duodenum, with dysplastic progression of the gastric type.

Virchows Arch 1999;435:452-7. 


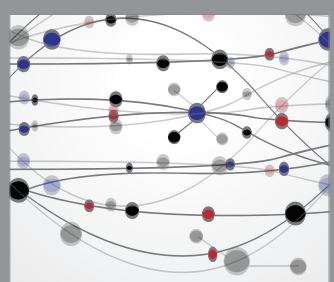

The Scientific World Journal
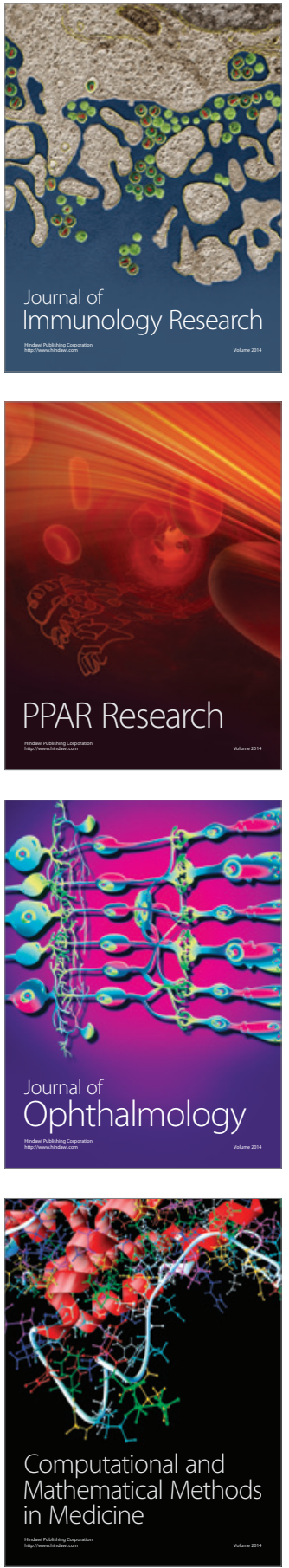

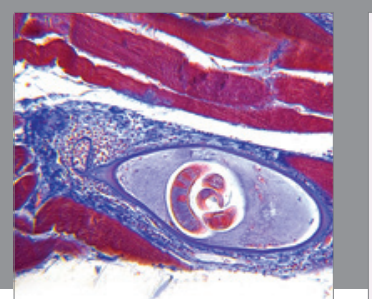

Gastroenterology Research and Practice

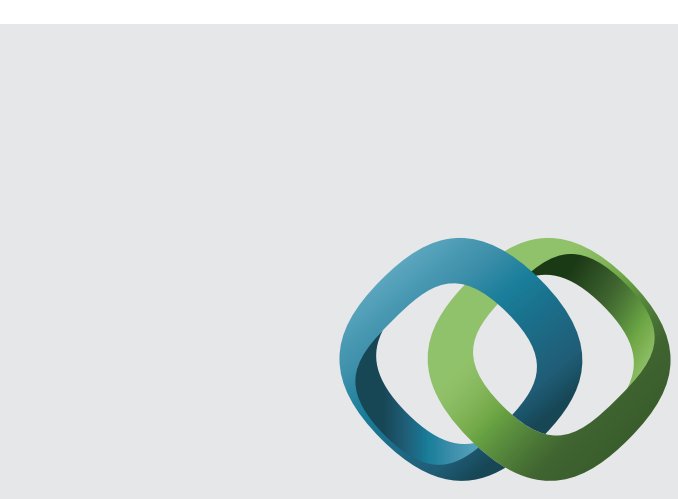

\section{Hindawi}

Submit your manuscripts at

http://www.hindawi.com
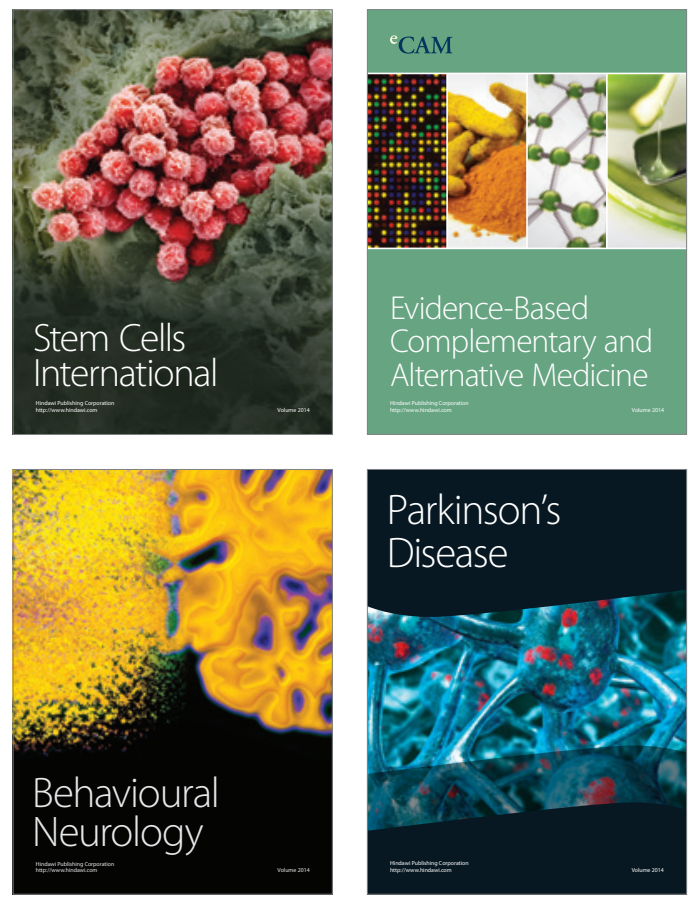
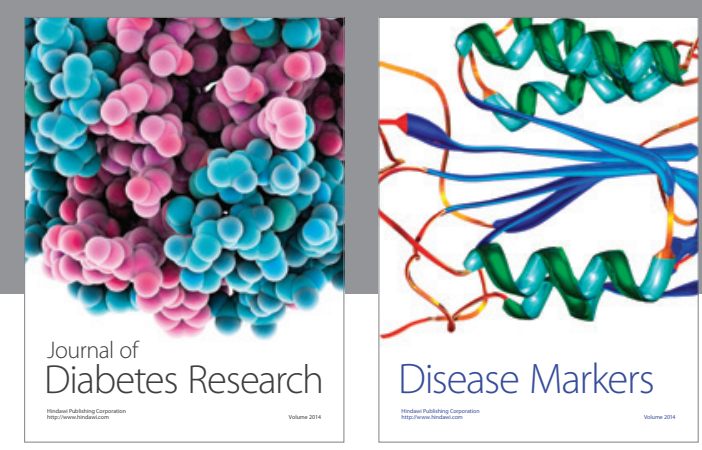

Disease Markers
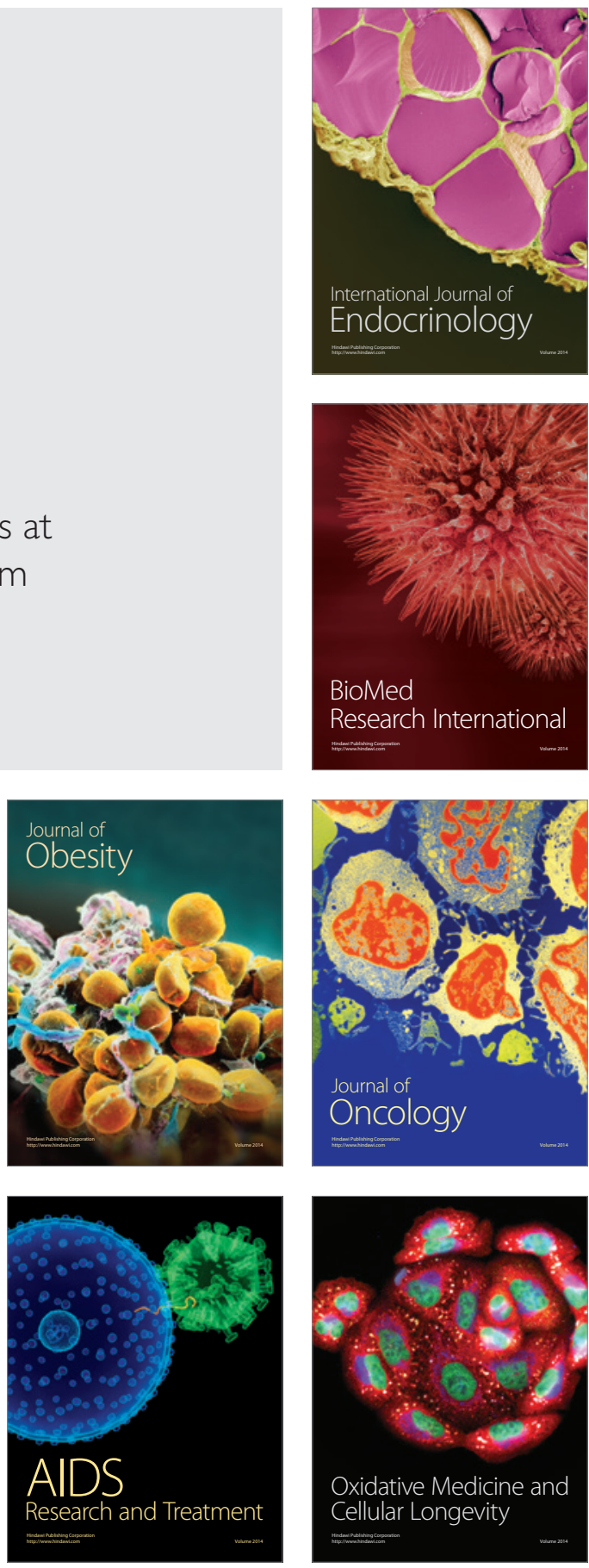